\title{
Cerebral amyloid angiopathy-related inflammation: a rare disease that needs to be diagnosed
}

\author{
Ioan Paul Voicu, ${ }^{1}$ Corrado Tagliati $\left(10,{ }^{2}\right.$ Samanta Sciamanna, ${ }^{3}$ Giuseppe Lanni ${ }^{2}$
}

'Department of Services, Radiology and MRI Unit, "G. Mazzini" Hospital, Teramo, Italy, ASL 4 Teramo, Teramo, Abruzzo, Italy

${ }^{2}$ Department of Services, Radiology Unit, "S. Liberatore" Hospital, Atri, Italy, ASL 4 Teramo, Teramo, Abruzzo, Italy ${ }^{3}$ Department of medicine, Neurology Unit, "G. Mazzini" Hospital, Teramo, Italy, ASL 4 Teramo, Teramo, Abruzzo, Italy

\section{Correspondence to}

Dr Corrado Tagliati; corrado.tagliati@gmail.com

Accepted 23 February 2021

\section{DESCRIPTION}

A 70-year-old man with persistent headache for 2 weeks presented to our emergency department due to sudden clinical worsening characterised by global aphasia, right lateral homonymous hemianopia and cognitive deterioration. A CT scan revealed left parietal and occipital hypodensity consistent with oedema. MRI fluid-attenuated inversion recovery (FLAIR) sequence (figure 1) confirmed subcortical oedema, associated with effacement of the overlying sulci, without associated diffusion restriction (figure 2) or contrast material enhancement. T2*-weighted sequence (figure 3 ) showed multiple small hypointense cortical and subcortical signal changes, consistent with microhaemorrhages. Based on MRI findings, a diagnosis of cerebral amyloid angiopathy-related inflammation (CAA-ri) was suggested. Therefore, oral steroid therapy was initiated and the patient fully recovered. ${ }^{1}$

CAA-ri is a disease subtype of cerebral amyloid angiopathy characterised by rapidly progressive cognitive decline, seizures, headaches, T2-weighted hyperintense MRI lesions, evidence of pre-existing CAA on susceptibility-weighted MRI sequences and neuropathological evidence of CAA-associated vascular inflammation. ${ }^{2}$

Some authors have suggested that clinical and radiological criteria may help diagnose a probable CAA-ri with good sensitivity and specificity, therefore avoiding cerebral biopsy. ${ }^{4}$ The diagnosis of

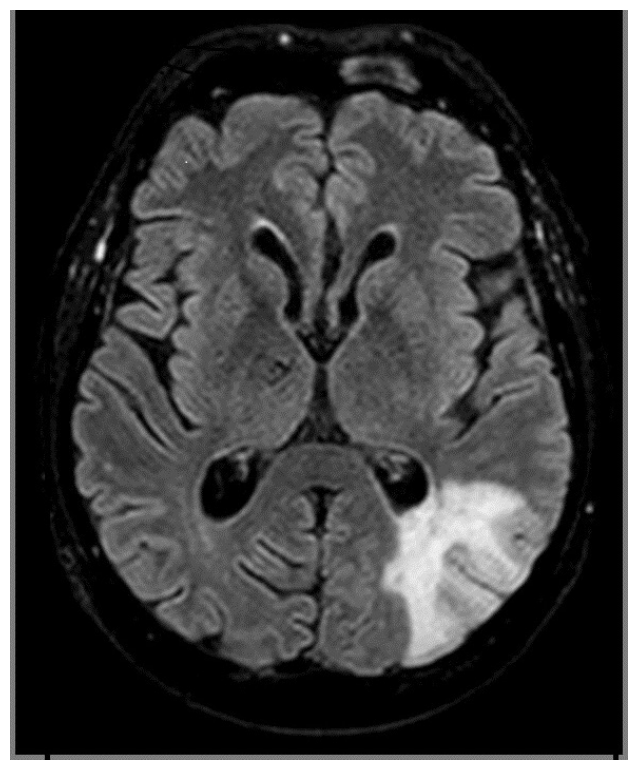

Figure 1 MRI fluid-attenuated inversion recovery sequence showed subcortical oedema and effacement of the overlying sulci.

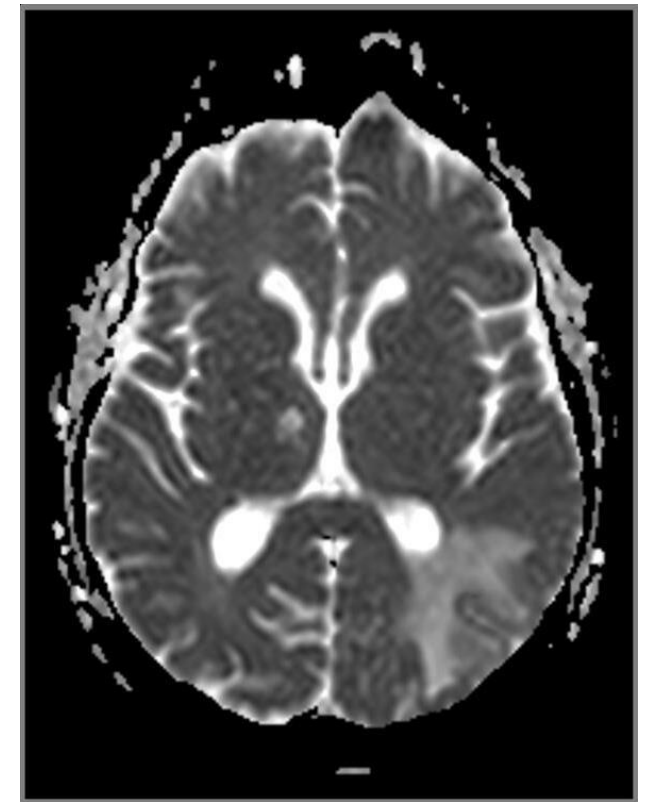

Figure 2 Apparent diffusion coefficient image showed hyperintense signal, suggesting vasogenic oedema.

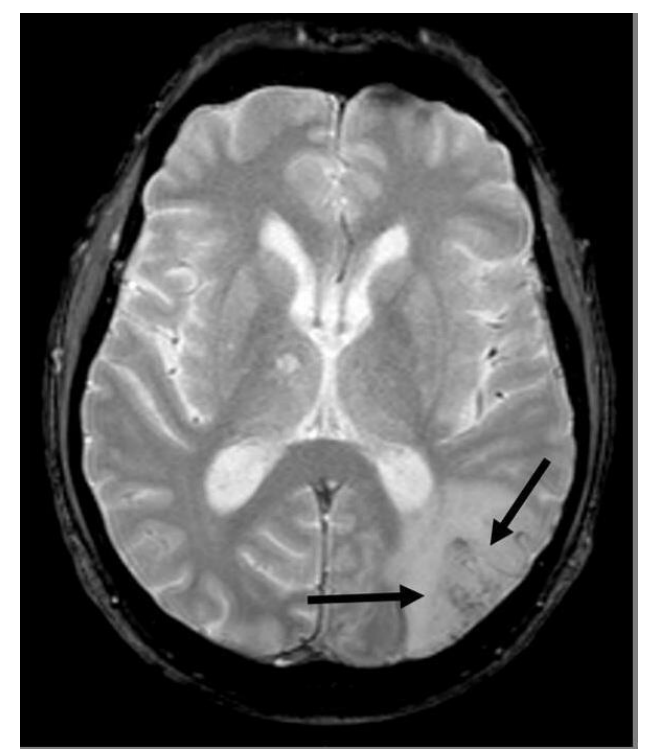

Figure $3 \mathrm{~T} 2^{*}$-weighted sequence showed multiple small hypointense cortical and subcortical signal changes, consistent with microhaemorrhages.

probable CAA-ri requires the following six findings: (1) acute or subacute onset of symptoms; (2) 40 years of age or older; (3) presentation with a variable combination of acute or subacute onset of headache, decrease in consciousness or 
behavioural change, focal neurological deficits and seizures; (4) MRI with patchy or confluent T2-weighted or FLAIR lesions, usually asymmetric, with or without mass effect and with or without leptomeningeal or parenchymal enhancement; (5) multiple lobar microhaemorrhages and/or recent or past lobar intracerebral haemorrhage; (6) absence of neoplastic, infectious or other cause. ${ }^{5}$

There is usually a favourable response to immunosuppressive therapy. However, some patients may have a fluctuating course or relentless progression. Therefore, CAA-ri diagnosis is very important in clinical practice as many patients respond to immunosuppressive therapy.

\section{Patient's perspective}

I am very grateful to the doctors who diagnosed this disease for being able to recover completely simply with corticosteroid therapy.

\section{Learning points}

- A diagnosis of probable cerebral amyloid angiopathy-related inflammation (CAA-ri) may be made on the basis of typical clinical and radiological findings without requiring a biopsy.

- CAA-ri diagnosis is very important in clinical practice as many patients respond to immunosuppressive therapy.
Acknowledgements The authors are grateful to the following individuals for their assistance, guidance and helpful discussions: Alfonsina Casalena, MD, PhD, and Gabriella Lucidi Pressanti, MD.

Contributors IPV, SS and CT have been involved in the preparation of this manuscript. GL revised the manuscript for intellectual content. All authors have read and approved the manuscript.

Funding The authors have not declared a specific grant for this research from any funding agency in the public, commercial or not-for-profit sectors.

Competing interests None declared.

Patient consent for publication Not required.

Provenance and peer review Not commissioned; externally peer reviewed.

\section{ORCID iD}

Corrado Tagliati http://orcid.org/0000-0002-4630-1090

\section{REFERENCES}

1 Rempe T, Sollero CEV, Rodriguez E, et al. Corticosteroids lead to short-term improvement in cerebral amyloid angiopathy-related inflammation. J Neuroimmunol 2020;348:577377.

2 Eng JA, Frosch MP, Choi K, et al. Clinical manifestations of cerebral amyloid angiopathy-related inflammation. Ann Neurol 2004;55:250-6.

3 Auriel E, Charidimou A, Gurol ME, et al. Validation of clinicoradiological criteria for the diagnosis of cerebral amyloid angiopathy-related inflammation. JAMA Neurol 2016;73:197-202.

4 Kinnecom C, Lev MH, Wendell L, et al. Course of cerebral amyloid angiopathy-related inflammation. Neurology 2007;68:1411-6.

5 Chung KK, Anderson NE, Hutchinson D, et al. Cerebral amyloid angiopathy related inflammation: three case reports and a review. J Neurol Neurosurg Psychiatry 2011;82:20-6.

Copyright 2021 BMJ Publishing Group. All rights reserved. For permission to reuse any of this content visit

https://www.bmj.com/company/products-services/rights-and-licensing/permissions/

BMJ Case Report Fellows may re-use this article for personal use and teaching without any further permission.

Become a Fellow of BMJ Case Reports today and you can:

- Submit as many cases as you like

- Enjoy fast sympathetic peer review and rapid publication of accepted articles

- Access all the published articles

- Re-use any of the published material for personal use and teaching without further permission

\section{Customer Service}

If you have any further queries about your subscription, please contact our customer services team on +44 (0) 2071111105 or via email at support@bmj.com.

Visit casereports.bmj.com for more articles like this and to become a Fellow 